Jurnal Ilmu Administrasi Publik 7 (2) (2019): 26-41

DOI: http://dx.doi.org/10.31289/publika.v7i2.2956

Jurnal Administrasi Publik

http://ojs.uma.ac.id/index.php/publikauma

\title{
Evaluasi Program Desa Mandiri Energi Berbasis Biogas di Desa Mekarjaya
}

\author{
Lulu Anastesi Sayekti * \\ *Program Studi Ilmu Administrasi Negara, Sekolah Tinggi Ilmu Administrasi, \\ Yogyakarta, Indonesia
}

Diterima Agustus 2019; Disetujui Oktober 2019; Dipublikasikan Desember 2019

\begin{abstract}
Abstrak
Tujuan penelitian ini adalah untuk mendiskripsikan evaluasi program Desa Mandiri Energi di Desa Mekarjaya, Kabupaten Cianjur, Jawa Barat. Penelitian dilakukan di Desa Mekarjaya Kabupaten Cianjur, UPTD ESDM Kabupaten Cianjur, dan Dinas PMD Kabupaten Cianjur. Penelitian dilakukan menggunakan pendekatan deskriptif dengan metode kualitatif. Pengumpulan data menggunakan wawancara, observasi, dan dokumentasi. Teknik analisis data menggunakan analisis data menurut Miles dan Huberman. Hasil penelitian menunjukkan bahwa Kriteria efektifitas (effectiveness), Kecukupan (Adequency), Kriteria Perataan (Equity), dan Kriteria Ketepatan (Appropriateness) belum optimal, meskipun Kriteria Responsivitas (Responsiveness) pada penelitian ini menunjukkan penilaian yang baik. Rekomendasi untuk program ini, yaitu program dapat diteruskan, namun perlu diperbaiki baik prosedur maupun penerapannya.
\end{abstract}

Kata kunci : Evaluasi, Program, Biogas

\section{Abstract}

The purpose of this research is to describe the evaluation of Energy Self-sufficient Village Program in Mekarjaya Village, Cianjur District. The study was conducted in Mekarjaya Village, UPTD ESDM Cianjur District, and DPMD Cianjur District. This research using descriptive approach with qualitative methode. Data collection was done by interview technique, observation, and documentation. Analysis Technique in this research is according to Miles and Huberman analysis technique. The result shows that effectiveness, adequency, equity, and appropiateness criterias aren't optimal, although responsiveness criteria shows a good appraisal. The recommendation for this program is to continue with improve its practices and procedures.

Keywords : Evaluation, Program, Biogas

How to Cite : Sayekti, A.,L. (2019). Evaluasi Program Desa Mandiri Energi Berbasis Biogas di Desa Mekarjaya, 7 (2) : 26-

*Corresponding author:
E-mail: lulusayekti84@gmail.com

P-ISSN-2549-9165

e-ISSN -2580-2011 


\section{PENDAHULUAN}

Penggunaan Energi Baru dan Terbarukan (EBT) di Indonesia masih minim. Meskipun Indonesia memiliki sumber EBT yang berlimpah, namun energi dari Bahan Bakar Minyak (BBM) dan gas masih sangat mendominasi. Untuk mendukung Millenium Development Goals (MDGs) Indonesia, seharusnya penggunaan EBT yang ramah lingkungan dapat dijadikan alternatif pengganti energi primer minyak dan gas yang menghasilkan emisi $\mathrm{CO}^{2}$ cukup besar.

Biogas merupakan salah satu alternatif yang dapat digunakan sebagai bahan bakar yang ramah lingkungan. EBT ini cukup murah, mudah, dan mampu menjangkau hingga pelosok desa. Biogas dapat berasal dari kotoran manusia, kotoran hewan, limbah rumah tangga, dan sampah biodegradable dalam kondisi anaerobik.

Melihat sumber daya yang ada, Propinsi Jawa barat memiliki potensi sebagai penghasil biogas yang cukup besar. Populasi ternak yang dapat mencapai 1 juta ekor di berbagai tempat dapat mendukung potensi biogas menjadi salah satu sumber energi alternatif yang dapat menggantikan BBM dan gas yang selama ini digunakan oleh masyarakat.
Biogas dari kotoran ternak lebih banyak digunakan karena memiliki nutrisi seimbang, mudah diencerkan, dan diolah secara biologi (Prihutama, dkk, 2017).

Permen ESDM No.32 tahun 2008 tentang Penyediaan, Pemanfaatan, dan Tata Niaga Bahan Bakar (Biofuel) sebagai Bahan Bakar Lain, mendefinisikan Desa Mandiri Energi adalah desa dimana masyarakatnya memiliki kemampuan memenuhi lebih dari 60\% kebutuhan energi (listrik dan bahan bakar) dan energi terbarukan yang dihasilkan melalui pendayagunaan potensi sumber daya setempat. Desa Mandiri Energi memiliki tujuan utama pengembangan Desa Mandiri Energi adalah mengurangi kemiskinan dan membuka lapangan kerja untuk mensubstitusi bahan bakar minyak (Widyaningsih,2014).

Menurut Taufiq dan Purwoko (2013), Desa Mandiri Energi merupakan program untuk mewujudkan potensi desa agar mampu memenuhi kebutuhan energinya sendiri, menciptakan lapangan pekerjaan, dan menghasilkan kegiatankegiatan lain yang produktif. Desa Mandiri Energi terdiri dari dua jenis, yaitu Desa Mandiri Energi yang berasal dari bahan bakar non nabati (energi makrohidro, tenaga surya dan biogas) dan Desa 
Mandiri Energi yang berasal dari bahan bakar nabati (biofuel). Sasaran dari program ini salah satunya adalah untuk melepaskan ketergantungan masyarakat desa terhadap BBM.

Untuk mendukung Pilot Project Desa Mandiri Energi (DME) dari Kementerian ESDM Jawa Barat, maka Kementerian PDT dan Dinas PMD Kabupaten Cianjur memberikan bantuan kepada dua desa di Kecamatan Campaka, Jawa Barat. Desa Mekarjaya sebagai salah satu desa yang menjadi percontohan DME mendapatkan bantuan berupa 28 ekor sapi, pembangunan kandang, dan 14 unit peralatan biogas.

Namun, kenyataanya program DME ini tidak berjalan seperti yang diharapkan. Kepala Desa Mekarjaya, Izin Suparman, pembangunan biogas di desanya dilakukan masih dengan cara-cara konvensional, yaitu dengan cara mengelola limbah pertanian dan kotoran ternak dengan peralatan yang dibuat oleh tangan-tangan kreatif warga masyarakat sehingga masih belum dapat menghasilkan biogas dalam jumlah banyak dan berkualitas tinggi.

Program DME di Desa Mekarjaya telah berlangsung lebih dari tiga tahun. Pelaku kebijakan seharusnya dapat menilai keberhasilan atau kegagalan program ini. Evaluasi program dapat dilakukan dengan menilai beberapa kriteria, yaitu kriteria efektivitas (effectiveness), kriteria kecukupan (adequency), kriteria perataan (equity), kriteria responsivitas (resonsiveness), dan kriteria ketepatan (appropriateness) (Dunn, 2003).

Energi Baru Terbarukan (EBT) yang digunakan pada program DME mencakup aspek keberlanjutan (sustainabillity), pengembangan daerah (Regional Development) dan ramah lingkungan (Pemprov Jateng, 2019). Keberlanjutan usaha biogas dapat dilihat dari 5 indikator keberlanjutan menurut Ilskog (2008) dalam Wahyudi, dkk (2015), yaitu dimensi teknik, ekonomi, sosial, lingkungan, dan kelembagaan. Dimensi teknik mengarah pada keberlanjutan bahan dan perbaikan yang mendukung biogas berjalan baik tanpa adanya masalah yang besar. Dimensi ekonomi difokuskan pada bantuan ekonomi, penambahan pendapatan, penghematan dan menciptakan lapangan pekerjaan.

Dimensi sosial berkaitan dengan kesehatan manusia dan memajukan persamaan gender. Dimensi lingkungan berkaitan dengan pengurangan 
pencemaran lingkungan. Dimensi kelembagaan berkaitan dengan partisipasi stakeholder dan pembangunan kapasitas.

Melalui evaluasi, terdapat beberapa rekomendasi bagi pembuat kebijakan untuk program mendatang, yaitu: untuk melanjutkan atau pun tidak melanjutkan program; program perlu diteruskan, namun perlu perbaikan pada prosedur dan penerapannya; perlu menambah atau mengembangkan strategi program yang spesifik dan teknik-teknik yang mendukung; program perlu diterapkan di tempat lain; perlu mengalokasikan sumberdaya-sumberdaya langka pada program-program yang kompetitif; perlu menolak atau menerima teori atau pendekatan kebijakan program (Weiss dalam Widodo, 2009).

Permasalahan yang ada menunjukkan pentingnya evaluasi program DME di Desa Mekarjaya. Evaluasi program DME berbasis biogas di Desa Mekarjaya perlu digali lebih dalam melalui penelitian agar dapat diketahui rekomendasi yang tepat bagi pembuat kebijakan untuk keberlangsungan program ini selanjutnya.

\section{METODE PENELITIAN}

Penelitian ini menggunakan metode deskriptif dengan pendekatan kualitatif. Menurut Ikbar (2014:156): “ Pendekatan kualitatif merupakan pendekatan penelitian berlandaskan fenomenologi dan paradigma konstruktivisme dalam mengembangkan ilmu pengetahuan". Menurut (Sugiyono, 2008) mengemukakan bahwa penelitian kualitatif deskriptif merupakan metode penelitian yang berlandaskan pada filsafat postpositivisme dan penulis sebagai indikator kunci. Penelitian dilakukan di UPTD ESDM Kabupaten Cianjur, Dinas PMD Kabupaten Cianjur, dan Desa Mekarjaya.

Teknik pengumpulan data menggunakan wawancara, observasi, dan dokumentasi. Teknik penetuan informan bersifat purposive. Sugiyono (2008:53) menyatakan: " Dalam penelitian kualitatif, teknik sampling yang sering digunakan adalah purposive sampling dan snowball sampling". Purposive sampling adalah pengambilan sumber data dengan pertimbangan tertentu, misalnya informan yang dipilih merupakan orangorang yang paling mengerti tentang penelitian yang dilakukan.

Informan yang dipilih dalam penelitian ini adalah Kepala Bagian Pemberdayaan Ekonomi DPMD Kabupaten Cianjur, Jawa Barat; Kepala Dinas Energi, Sumberdaya dan Mineral 
(ESDM) Kabupaten Cianjur, Jawa Barat; Kepala Desa Mekarjaya, kabupaten Cianjur, Jawa Barat; dan 5 (lima) orang peserta DME di desa Mekarjaya. Teknik analisa data dalam penelitian ini menggunakan teknik menurut Miles dan Huberman.

Miles dan Huberman (1984) dalam Sugiyono ( 2008) mengemukakan bahwa analisis data kualitatif berlangsung secara terus-menerus hingga tuntas hingga data jenuh dan tidak dapat dianalisis lagi. Aktivitas analisis data tersebut, yaitu reduksi data, display data, dan kesimpulan/verifikasi.

\section{HASIL DAN PEMBAHASAN}

Desa Mekarjaya merupakan salah satu desa di Kecamatan Campaka, Cianjur Tengah. Desa Mekarjaya memiliki luas wilayah $1.604 .546 \mathrm{~km}$ dan berbatasan dengan beberapa daerah. Sebelah utara, Desa Mekarjaya berbatasan dengan Desa Margaluyu. Sebelah Timur, Desa Mekarjaya berbatasan dengan Kabupaten Bandung. Sebelah Selatan dan Barat, Desa Mekarjaya berdampingan dengan Desa Cempaka Warna dan Desa Cidadap (BPS, 2015).

Menurut (Dunn, 2003), terdapat beberapa kriteria untuk mengevaluasi sebuah program, yaitu efektivitas (effectiveness), Kecukupan (Adequency), Perataan (Equity), Responsivitas (Resonsiveness), dan ketepatan (Appropriateness).

Efektifitas (effectiveness) menunjukkan bahwa hasil yang diinginkan telah tercapai.

Pada kriteria kecukupan (adequency) dilakukan analisis pada aspek dukungan dana atau alokasi dana yang diberikan kepada KK peserta Program DME. Kriteria perataan (equity) menekankan pada distribusi bantuan yang diberikan baik materil maupun bantuan teknis secara merata kepada setiap KK peserta program. Kriteria responsivitas (responsiveness) berkenaan dengan seberapa jauh suatu kebijakan/program dapat memuaskan kebutuhan, preferensi atau nilai kelompok-kelompok masyarakat. Kriteria ketepatan (appropiateness) berhubungan dengan hasil yang dicapai mendatangkan manfaat bagi peserta program DME di Desa Mekarjaya.

Kriteria efektifitas program DME dilihat dari ketercapaian tujuan program, yaitu menuju swasembada energi, pemanfaatan biogas sebagai salah satu EBT, partisipasi masyarakat. Desa swasembada energi adalah desa yang mampu memenuhi lebih dari 60\% 
kebutuhan energinya (listik dan bahan bakar) melalui energi terbarukan dengan pendayagunaan potensi sumber daya setempat. Tujuan lain dari program DME adalah pemanfaatan EBT sebagai alternatif energi yang dapat digunakan secara berkelanjutan. Biogas merupakan salah satu EBT yang berpotensi untuk digunakan secara terus-menerus terutama di daerah yang memiliki banyak hewan ternak seperti di Kabupaten Cianjur, Jawa Barat. Partisipasi yang tinggi akan berkaitan dengan capaian yang akan diperoleh dari terlaksananya program DME di Desa Mekarjaya.

Tabel 1. Jumlah Rumah Tangga di Kecamatan Campaka, Cianjur, Jawa Barat

\begin{tabular}{llcc}
\hline No. & \multicolumn{1}{c}{ Nama Desa } & $\begin{array}{c}\text { Jumlah Rumah } \\
\text { Tangga }\end{array}$ & Jumlah Penduduk \\
\hline 1. & Wangunjaya & 1.857 & 5.536 \\
2. & Suadana & 1.669 & 5.492 \\
3. & Karyamukti & 1.752 & 5.386 \\
4. & Cimenteng & 1.994 & 6.407 \\
5. & Girimukti & 1.893 & 6.532 \\
6. & Susukan & 2.217 & 7.736 \\
7. & Sukajadi & 2.235 & 6.752 \\
8. & Margaluyu & 1.772 & 5.573 \\
9. & Mekarjaya & 1.796 & 5.635 \\
10. & Cidadap & 1.731 & 5.731 \\
11. & Cempaka & 1.712 & 5.759 \\
\hline
\end{tabular}

Sumber: BPS Kabupaten Cianjur, 2018

Jumlah keluarga/rumah tangga di

Desa Mekarjaya berjumlah 1.796 Keluarga. Tentunya jumlah ini tidak sebanding dengan bantuan unit biogas yang diperoleh, yaitu berjumlah 14 unit biogas. Dalam kenyataannya di lapangan, 1 unit biogas hanya mampu untuk mengaliri 1 rumah, sehingga adanya 14 unit biogas hanya untuk mengaliri 14 rumah yang ada di Desa Mekarjaya. Jumlah rumah tangga di Desa Mekarjaya sebanyak 1.796 Kepala Keluarga, dengan perbandingan 14 rumah pengguna biogas, maka persentase penggunaan biogas di desa tersebut belum mencapai 60\%, namun hanya 0,79\% dari jumlah KK keseluruhan. Bioenergi yang dihasilkan dari setiap kubah pengelola biogas hanya mampu membantu beberapa keluarga sehingga belum dapat mencapai swasembada energi untuk seluruh Desa Mekarjaya. 
Tabel 2. Energi yang Dihasilkan dari Biogas

\begin{tabular}{cccccc}
\hline Skenario & Kondisi & $\begin{array}{c}\text { Total Kebutuhan } \\
\text { Energi }\end{array}$ & $\begin{array}{c}\text { Energi yang } \\
\text { Dihasilkan }\end{array}$ & $\begin{array}{c}\text { Kebutuhan } \\
\text { Kotoran } \\
\text { dengan } \\
\text { Biogas }\end{array}$ & $\begin{array}{c}\text { Jumlah } \\
\text { Sapi }\end{array}$ \\
\hline Skenario 1 & Biasa & $808,20 \mathrm{kWh} /$ hari & $126 \mathrm{kWh} /$ hari & $84 \mathrm{~m}^{3}$ & 28 sapi \\
Skenario 2 & $60 \%$ & $808,20 \mathrm{kWh} / \mathrm{hari}$ & $\begin{array}{c}484,92 \\
\text { pemenuhan }\end{array}$ & $324,28 \mathrm{~m}^{3}$ & 108 \\
& & & & sapi \\
& kebutuhan & & & \\
& energi & & & \\
& listrik & & & \\
\hline
\end{tabular}

Sumber: Olahan Penulis, 2019

Jumlah keluarga di Desa

Desa Mekarjaya belum mencapai

Mekarjaya adalah $1.796 \mathrm{KK}$ dan standar swasembada energi seperti yang listrik yang digunakan adalah 450 diharapkan dalam program DME selama 4 watt/keluarga. Jadi, kebutuhan energi oleh masyarakat Desa Mekarjaya adalah $808,20 \mathrm{kWh}$ per hari. Hanya 28 sapi dari 14 keluarga yang digunakan untuk menghasilkan biogas dan hanya terdapat 14 titik kubah biogas dengan tipe $6 \mathrm{~m}^{3}$. Sekenario pertama menunjukkan bahwa hanya 15,6\% kapasitas energi yang dihasilkan. Sekenario kedua dengan perhitungan $60 \%$ kebutuhan energi terpenuhi agar dapat menjadi Desa Mandiri energi, Desa Mekarja harus mengoptimalkan $324,28 \mathrm{~m}^{3}$ kotoran sapi. Hal ini berarti harus terdapat 54 unit biogas yang harus dibangun dan membutuhkan minimal 108 ekor sapi (Listyawati, 2014). (empat tahun). Peserta program belum memperoleh energi secara maksimal melalui pemanfaatan biogas yang dihasilkan. Program DME yang dicanangkan Pemdes dan DPMD juga belum mampu untuk memenuhi jumlah KK yang ada di Desa Mekarjaya, terutama masyarakat dengan ekonomi kebawah yang tinggal di desa tersebut. Biogas yang dihasilkan cukup membantu peserta program dalam kehidupan sehari-hari, namun belum mencukupi dalam memenuhi energi yang diharapkan sebagai DME.

Hasi bioenergi yang didapat hanya mampu mengurangi pengeluaran untuk membeli gas LPG sebagai energi untuk memasak. Sehingga pemenuhan 60\% 
kebutuhan energi Desa Mekarjaya secara mandiri dirasa masih jauh.

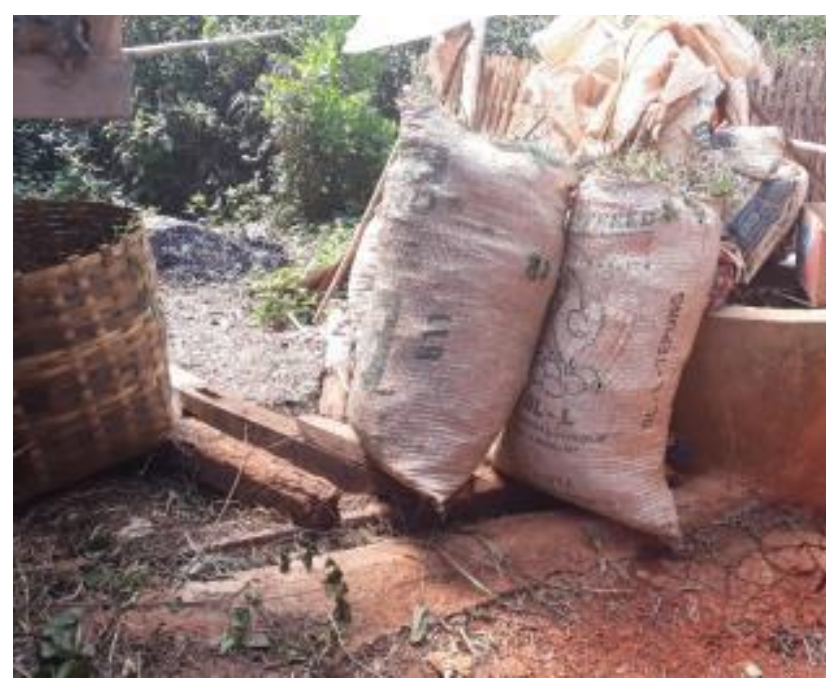

Gambar 1. Unit Biogas yang Rusak Sumber: Observasi Penulis, 2019

Hasil observasi dan wawancara menunjukkan bahwa Desa Mekarjaya belum mampu menjadikan biogas sebagai EBT secara berkelanjutan. Hal ini dikarenakan beberapa kendala yang diadapi oleh peserta program, antara lain proses biogas yang masih konvensional sehingga menimbulkan bau yang tidak sedap, kerusakan alat, dan sosialisasi yang masih kurang. Menurut (Wiyono, 2014), tujuan pemberdayaan masyarakat program Desa Mandiri Energi di Desa Sidomulyo, Kabupateng Tulungagung dapat tercapai dikarenakan adanya sosialisasi program yang baik dari pemerintah.
Motivasi peserta program DME berbasis biogas di Desa Mekarjaya untuk mengikuti program cukup tinggi. Semua peserta mengharapkan dapat memanfaatkan biogas sebagai salah satu alternatif energi, namun keterbatasan bantuan dan dana dari pemerintah menyebabkan hanya beberapa peserta yang dapat menggunakan biogas.

Jumlah kotoran dari ternak sapi yang memadai dapat menjadi sumber energi yang dapat dimanfaatkan. Menurut teori Amstein ,1969 (dalam Widaningsih ,2014) tingkat partisipasi peserta program DME baru mencapai tingkat partisipasi terapi (perbaikan). Masyarakat ikut terlibat dalam program DME, namun belum dilandasi oleh suatu dorongan mental, psikologis untuk memberikan kontribusi dalam program. Masyarakat mulai menyadari bahwa program DME membawa manfaat bagi perbaikan kehidupan ekonomi. Partisipasi peserta program non-biogas lebih pada kegiatan ternak sapi hasil dari ternak yang diperbantukan oleh pemerintah.

Kriteria Efektivitas (Efectiveness) dalam program DME berbasis biogas di Desa Mekarjaya secara keseluruhan belum dapat terlaksana secara optimal. Belum terlihat ketercapaian tujuan program 
seperti yang diharapkan. Desa Mekarjaya belum mampu mencapai swasemda energi karena produksi biogas yang dihasilkan masih sedikit. Biogas yang dihasilkan belum dapat menjadi alternatif EBT yang berkelanjutan karena kendala yang terjadi, seperti peralatan rusak yang tidak dapat diperbaiki sehingga sumur pengaduk menjadi kering, teknik pengelolaan biogas yang masih konvensional, dan budaya masyarakat yang menganggap kotoran sebagai sesuatu yang tidak baik bagi kesehatan. Partisipasi peserta program DME cukup tinggi. Peserta pengguna biogas antusias dalam pengelolaan biogas, namun tidak semua peserta menjadi pengguna biogas. Hal ini dikarenakan keterbatasan bantuan yang diberikan. Para peserta sangat mengharapkan bantuan unit biogas dapat ditambah untuk membantu perekonomian keluarga sehari-hari.

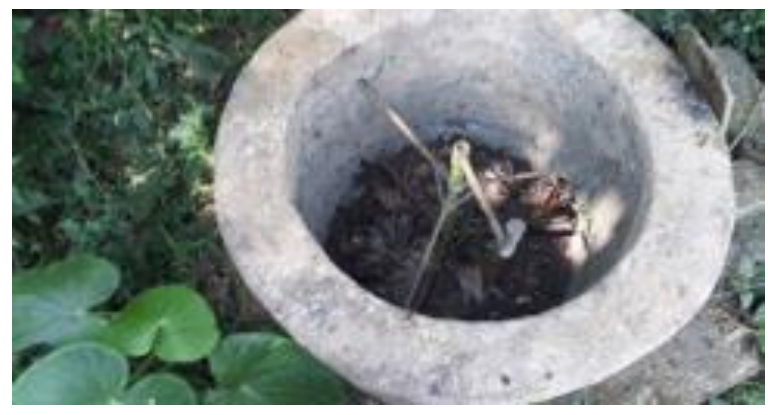

Gambar 2. Sumur Pengaduk yang Kering Sumber: Observasi Penulis, 2019
Kriteria Kecukupan (Adequency) bertujuan untuk memberikan gambaran apakah bantuan yang diberikan dari pemerintah dapat menunjang terlaksananya program DME berbasis biogas ini secara merata. Desa Mekarjaya mendapatkan bantuan sarana dan prasarana pengolah biogas yang lebih banyak dari pemerintah jika dibandingkan dengan desa lainnya. Pada tahun 2014, Desa Mekarjaya mendapat bantuan digester biogas sebanyak 4 unit. Selanjutnya, tahun berikutnya bantuan digester biogas ditambah 10 unit sehingga total bangunan digester yang diberikan sebanyak 14 unit. Selain bangunan digester biogas, pemerintah juga memberikan bantuan sebanyak 28 ternak sapi. 
Tebel 2. Bantuan Sarana dan Prasarana Pengolah Biogas Tahun 2014-2016

\begin{tabular}{|c|c|c|c|c|c|}
\hline & \multirow[t]{2}{*}{ Bantuan } & \multirow[t]{2}{*}{ Lokasi } & \multicolumn{3}{|c|}{ Tahun } \\
\hline & & & 2014 & 2015 & 2016 \\
\hline 1. & Bangunan Digester & Cidaun/Cidamar & 4 unit & & \\
\hline 2. & Bangunan Digester & $\begin{array}{c}\text { Desa } \\
\text { Pasawahan } \\
\text { Kecamatan } \\
\text { Takokok } \\
\end{array}$ & 4 unit & & \\
\hline 3. & Bangunan Digester & Desa & 1 unit & & \\
\hline & $\begin{array}{c}\text { Bangunan Kandang } \\
\text { Sapi }\end{array}$ & $\begin{array}{l}\text { Mentengsari } \\
\text { Kecamatan } \\
\text { Cikalongkulon }\end{array}$ & 4 unit & & \\
\hline 4. & Bangunan Digester & & 4 unit & & \\
\hline & $\begin{array}{l}\text { Pelatihan beternak } \\
\text { cacing }\end{array}$ & $\begin{array}{c}\text { Desa Cibereum } \\
\text { Kecamatan } \\
\text { Cugenang }\end{array}$ & & & \\
\hline 5. & Bangunan Digester & $\begin{array}{c}\text { Desa Mekarjaya } \\
\text { Kabupaten } \\
\text { Cempaka }\end{array}$ & & & \\
\hline & APBD II & & 4 unit & 3 unit & \\
\hline & $\begin{array}{c}\text { Kemendes dan } \\
\text { PDT }\end{array}$ & & & 7 unit & \\
\hline & $\begin{array}{c}\text { Pelatihan } \\
\text { berternak cacing }\end{array}$ & & & & 1 kali \\
\hline & $\begin{array}{c}\text { Bantuan ternak } \\
\text { sapi (kemendes) }\end{array}$ & & & & $\begin{array}{c}28 \\
\text { ekor }\end{array}$ \\
\hline 6 & $\begin{array}{l}\text { Bantuan ternak } \\
\text { sapi (kemendes) }\end{array}$ & $\begin{array}{c}\text { Desa Girimukti } \\
\text { Kecamatan } \\
\text { Cempaka }\end{array}$ & & & $\begin{array}{c}28 \\
\text { ekor }\end{array}$ \\
\hline & Bangunan Digester & & & & 7 unit \\
\hline
\end{tabular}

Sumber: Renstra DPMD, 2014-2016

Bantuan pengolah biogas di Desa Mekarjaya lebih banyak jika dibandingkan dengan desa lainnya. Namun, kenyataannya jumlah bantuan yang diberikan ini belum mencukupi untuk membangun Desa Mandiri Energi. Masih banyak peserta program yang tidak mendapatkan digester untuk menghasilkan biogas. Bantuan pemerintah dalam program pemberdayaan DME di Desa Mekarjaya dari tahun 2014 hingga 2016 tidak mencukupi bagi keseluruhan peserta program yang berjumlah $75 \mathrm{KK}$. Selain itu, hingga saat ini belum ada tambahan digester biogas yang diperbantukan lagi ke Desa Mekarjaya.

Kriteria Kecukupan (Adequency) dalam program DME berbasis biogas di 
Desa Mekarjaya belum optimal. Hal ini terlihat dari bantuan sarana, prasarana, dan penyuluhan yang dirasakan kurang bagi $75 \mathrm{KK}$ peserta program. Peserta pengguna biogas juga mengluhkan kurangnya sosialisasi dan perawatan peralatan biogas dari pemerintah sehingga peralatan biogas yang rusak akan dibiarkan begitu saja.

Kriteria Perataan (Equity) menekankan pada distribusi bantuan yang diberikan baik materil maupun bantuan teknis secara merata kepada setiap KK peserta program. Di desa mekarjaya, bantuan digester dan ternak sapi yang diberikan oleh pemerintah pada tahun 2014 hingga 2016 untuk menunjang program DME berbasis biogas di Desa Mekarjaya masih sangat kurang. Akibatnya pendistribusian bantuan juga tidak dapat merata.

Dari keseluruhan jumlah KK di Desa Mekarjaya, terseleksi 75 KK yang mendapatkan bantuan. Bangunan Digester atau Kubah Biogas berjumlah 14 unit dipergunakan secara berkelompok. Namun, pada kenyataannya, satu kubah hanya dapat mengaliri satu rumah. Hal ini dikarenakan letak kubah biogas yang jauh antar anggota kelompok sehingga banyak anggota kelompok yang enggan menggunakan kubah.kepada semua KK peserta program.

Saluran biogas cukup jauh dari dapur rumah peserta program. Secara teknis akan membutuhkan saluran yang panjang untuk rumah peserta yang jauh dari kubah biogas. Kenyataan di lapangan, hanya satu saluran yang dibangun pada setiap kubah biogas sehingga tidak semua peserta program dapat menikmati dan memanfaatkan biogas yang dihasilkan.

Tabel 3. Daftar Peserta Program DME berbasis Biogas di Desa Mekarjaya yang Mendapatkan Digester Biogas

\begin{tabular}{|l|l|l|}
\hline \multicolumn{1}{|c|}{ No } & \multicolumn{1}{|c|}{ Nama } & \multicolumn{1}{c|}{ Pekerjaan } \\
\hline 1. & T. Jubadillah & Kades \\
\hline 2. & Dayat & Ketua Kelompok \\
\hline 3. & Khohir & Petani dan Peternak \\
\hline 4. & Toha & Petani dan Peternak \\
\hline 5. & Iyana & Petani dan Peternak \\
\hline 6. & Aboet & Petani dan Peternak \\
\hline 7. & Rukmana & Petani dan Peternak \\
\hline 8. & Dahlan & Petani dan Peternak \\
\hline 9. & Kardi & Petani dan Peternak \\
\hline 10. & Aep & Petani dan Peternak \\
\hline 11. & Nana & Petani dan Peternak \\
\hline 12. & Khosidin & Petani dan Peternak \\
\hline 13 & Mukmin & Petani dan Peternak \\
\hline 14. & Wahyu & Petani dan Peternak \\
\hline
\end{tabular}

Sumber: Hasil Observasi, 2019

Hanya 14 KK yang menggunakan biogas dari $75 \mathrm{KK}$ terseleksi sebelumnya. Peserta program lainnya mendapatkan bantuan berupa ternak peranakan pertama dari 28 ternak sapi yang diberikan untuk program ini. Setiap 
peserta pada akhirnya akan memiliki satu sapi hasil ternak sebelumnya. Namun, bantuan unit biogas belum ada penambahan hingga saat ini. Selain itu, belum ada bantuan teknis yang dirasakan oleh peserta pengguna biogas sehingga alat yang rusak tidak dapat diganti dan unit biogas tidak dapat berfungsi seperti biasanya.

Tabel 5. Persentase Jumlah KK Peserta DME

\begin{tabular}{|l|c|}
\hline Pengguna Biogas & Jumlah \\
\hline Jumlah Keluarga & 1.796 \\
\hline Jumlah Peserta DME & 75 \\
\hline $\begin{array}{l}\text { Jumlah Keluarga Pengguna } \\
\text { Biogas }\end{array}$ & 14 \\
\hline $\begin{array}{l}\text { Jumlah Keluarga Peternak Non- } \\
\text { Biogas }\end{array}$ & 63 \\
\hline
\end{tabular}

Sumber: Olahan Penulis, 2019

Jumlah peserta DME hanya sebesar $4,1 \%$ dari jumlah keluarga di Desa Mekarjaya. Jumlah keluarga pengguna biogas adalah $18,7 \%$ dari jumlah peserta terpilih. Sedangkan, jumlah peternak yang tidak menggunakan biogas lebih banyak, yaitu $84 \%$ dari jumlah peserta.

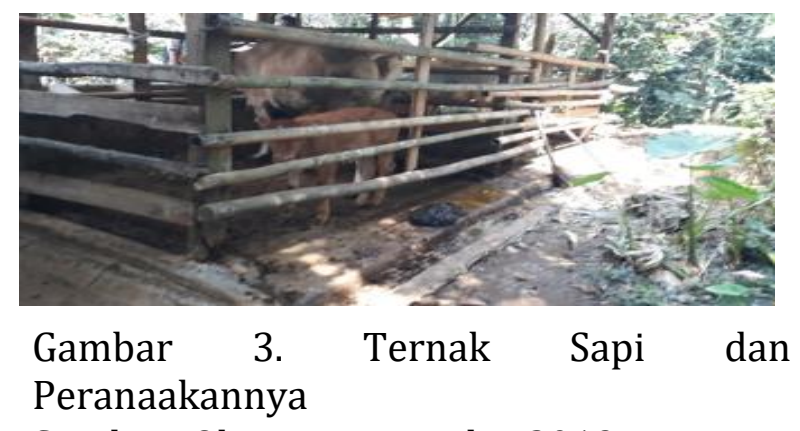

Sumber: Observasi Penulis, 2019
Kriteria Perataan (Equity) di Desa Mekarjaya belum optimal. Biogas belum dapat dihasilkan oleh semua peserta karena tidak semua peserta memiliki unit biogas. Meskipun semua peserta pada akhirnya akan mendapatkan sapi, namun peserta tetap harus menunggu sapi bantuan pemerintah beranak karena anak-ana sapi tersebut akan dibagibagikan kepada peserta lain yang belum memiliki sapi.

Kriteria

Responsivitas (Responsiveness) berkenaan dengan seberapa jauh suatu kebijakan/program dapat memuaskan kebutuhan, preferensi atau nilai kelompok-kelompok masyarakat. Dalam program DME ini, indikator yang digunakan dalam pemenuhan kriteria responsivitas adalah kepuasan peserta program (KK) dan dampak yang ditimbulkan dari Program DME berbasis biogas di Desa Mekarjaya.

Kriteria Responsivitas pada penelitian ini menunjukkan penilaian yang baik. Hal ini terlihat dari hasil wawancara kepada peserta program bahwa semua peserta merasa puas dengan adanya program dan bantuan unit biogas yang diberikan. Program DME berbasis biogas ini memberikan dampak yang positif bagi peserta program. Bagi peserta program 
pengguna biogas, energi biogas yang diproduksi dapat dijadikan alternatif energi pengganti LPG yang biasanya dibeli. Bagi peserta program pada umumnya (non-biogas), ternak sapi yang diberikan akan membantu perekonomian keluarga apabila dapat diperjualbelikan. Sehingga dapat disimpulkan bahwa kriteria responsivitas pada program DME berbasis biogas di Desa Mekarjaya sudah optimal.

Ketepatan

(Appropiateness) berhubungan dengan hasil yang dicapai mendatangkan manfaat bagi peserta program DME di Desa Mekarjaya, yaitu kemampuan peserta DME untuk memproduksi energinya sendiri, kemampuan peserta untuk mengembangkan kapasitasnya, program DME mampu menciptakan lapangan kerja dan mampu mengurangi tingkat kemiskinan di Desa Mekarjaya.

Desa Mekarjaya belum dapat dikatakan memproduksi energinya sendiri, karena lingkup yang dihasilkan masih sedikit. Biogas yang dihasilkan hanya mampu untuk memenuhi kebutuhan energi untuk memasak seharihari. Kebutuhan energi masih tergantung pada LPG.
Peserta program DME di Desa Mekarjaya belum mampu untuk mengembangkan kapasitas mereka, energi yang didapat hanya mampu untuk memasak dan jumlahnya terbatas. Menurut Wijayanti (2017) melalui perhitungan matematis, biogas merupakan investasi yang sangat menguntungkan jika dapat dimanfaatkan secara maksimal oleh masyarakat pengguna biogas. Modal untuk membuat digester akan kembali dalam satu tahun. Pengembangkan kapasitas energi harus didukung oleh keinginan peserta dan didukung oleh pemerintah. Jumlah energi biogas yang dihasilkan sangat tergantung dari upaya pengelola biogas melalui jumlah kotoran sapi yang dimasukkan, proses pengerjaan yang sesuai dengan prosedur sehingga dapat menghasilkan biogas yang sesuai dengan harapan. Jumlah input kotoran sapi akan mempengaruhi jumlah output biogas yang dihasilkan (Prihutama, 2017).

Program DME mampu untuk meningkatkan perekonomian mereka, tetapi tidak signifikan. Hal ini dikarenakan biogas hanya mampu untuk mengurangi penggunaan gas LPG atau menekan biaya pembelian LPG. Sebelum menggunakan biogas, peserta membeli LPG 3 atau 4 
tabung gas LPG $3 \mathrm{Kg}$ per bulan. Namun, setelah menggunakan biogas, pengeluaran untuk membeli LPG berkurang menjadi hanya 2 tabung per bulan.

Susilo, dkk (2016) menyatakan bahwa sektor peternakan terutama peternakan sapi dapat menjadi solusi untuk menekan bahan bakar bahkan bahan bakar kayu. Penggunaan biogas dapat menghemat biaya belanja energi dalam setahun. Pemanfaatan biogas sebagai sumber energi di pedesaan dapat memberikan multiple effect dan dapat menjadi pengerak pembangunan di desa. Produk-produk olahan yang dihasilkan dapat diberi green labelling dan menjadi nilai tambah.

Kriteria Ketepatan (Appropiateness) dalam program DME berbasis biogas di Desa Mekarjaya belum optimal. Peserta sudah mampu memproduksi energinya sendiri, namun masih terbatas untuk kebutuhan memasak. Lapangan pekerjaan yang dapat diciptakan dari Program DME berbasis biogas di Desa Mekarjaya belum banyak, hanya Peternak Sapi dan Penghasil Pupuk Kompos. Pengurangan tingkat kemiskinan di Desa Mekarjaya dari hasil program DME berbasis biogas ini belum terlihat secara signifikan karena biogas hanya dapat mengurangi biaya pembelian LPG setiap bulan.

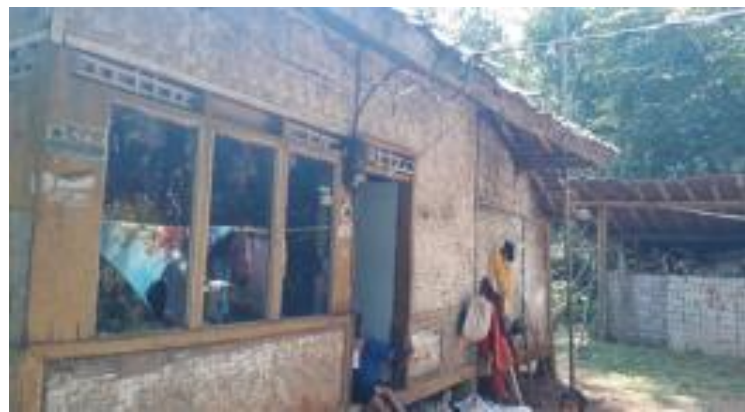

Gambar 3. Ternak Sapi dan Peranaakannya

Sumber: Observasi Penulis, 2019

Kebijakan publik yang baik menurut Dunn (2013) adalah kebijakan yang memenuhi kriteria evaluasi kebijakan publik, antara lain efektivitas (effectiveness), Kecukupan (Adequency), Perataan (Equity), Responsivitas (Resonsiveness), dan ketepatan (Appropriateness). Hasil penelitian menunjukkan bahwa kelima kriteria tersebut belum semuanya terpenuhi.

\section{Kriteria Efektivitas (effectiveness)} belum terpenuhi karena belum semua tujuan program DME di Desa Mekarjaya dapat terwujud. Kriteria Kecukupan (Adequency) belum terpenuhi karena bantuan yang dirasakan oleh peserta program masih kurang, begitu pula sosialisasi dan pendampingan yang diberikan oleh pemeintah. Kriteria Perataan (Equity) belum terpenuhi karena 
masih banyak masyarakat bahkan peserta program yang belum dapat menggunakan biogas. Kriteria Responsivitas (Resonsiveness) yang telah terpenuhi karena masyarakat dan peserta program merasa puas dan terbantu secara ekonomi dengan adanya program DME ini. Kriteria Ketepatan (Appropiateness) belum terpenuhi karena program DME di Desa Mekarjaya dirasa belum memberikan manfaat yang optimal bagi masyarakat dan peserta program.

\section{KESIMPULAN}

Berdasarkan kriteria-kriteria evaluasi yang digunakan, maka program DME di Desa Mekarjaya, Kabupaten Cianjur, Jawa Barat dinilai belum baik. Dari kelima kriteria evaluasi kebijakan, hanya satu kriteria yang dinilai sudah baik, yaitu kriteria Responsivitas (Resonsiveness). Rekomendasi untuk program ini, yaitu program dapat diteruskan, namun perlu diperbaiki baik prosedur maupun penerapannya. Berdasarkan penilaian kelima kriteria yang dinilai dalam evaluasi program DME di Desa Mekarjaya, Kabupaten Cianjur, maka terdapat beberapa masukkan yang dapat disampaikan, yaitu perlu adanya tambahan bantuan baik peralatan, materil, maupun teknis agar Desa Mekarjaya dapat memenuhi kriteria sebagai Desa Mandiri Energi, serta peningkatan koordinasi antar lembaga terkait untuk mewujudkan program Desa Mandiri Energi.

\section{UCAPAN TERIMAKASIH}

Tim peneliti mengucapkan terimakasih kepada Kemenristek Dikti Republik Indonesia yang telah mendanai penelitian kami pada skema Penelitian Dosen Pemula tahun anggaran 2019.

\section{DAFTAR PUSTAKA}

Dinas Pemberdayaan Masyarakat dan Desa Kabupaten Cianjur. 2016. Rencana Strategis (RENSTRA) Dinas Pemberdayaan Masyarakat dan Desa Kabupaten Cianjur untuk Periode Tahun Anggaran 2016-2021. Cianjur: DPMD.

Dunn, William, 2003. Analisis Kebijakan Publik. Jogjakarta : Gadjah Mada University.

Badan Pusat Statistik Kabupaten Cianjur. 2015. Statistik Daerah Kecamatan Campaka 2015. ISSN: 3203.15.49, Katalog: 1102002.3203.110.

Badan Pusat Statistik Kabupaten Cianjur. 2018. Kecamatan Campaka dalam Angka. ISSN: 32030.1826, Katalog: 1102001.3203110.

Listyawati, Ratih Novi, dkk. 2014. Evaluation of Energy Self-Sufficient Village by Means of EmergyIndices. Procedia Environmental Sciences 20 ( 2014 ) 30 - 39. 4th International 
Conference on Sustainable Future for Human Security, SustaiN 2013.

Pemerintah Propinsi Jawa Tengah. 2019. Sosialisasi Lomba Desa Mandiri Energi Propinsi Jawa Tengah. Semarang: Tim Juri Lomba Desa Mandiri Energi.

Prihutama, Faiz Akbar dkk. 2017. Pemanfaatan Biogas sebagai Energi Alternatif Ramah Lingkungan Daerah Desa Monggol, Kabupaten Gunung Kidul. SNITT-Politeknik Negeri Balikpapan 2017: ISBN:978602-51450-0-1.

Sugiyono. 2008. Memahami Penelitian Kualitatif. Bandung: Alfabeta.

Taufiq, dkk. 2016. Sistem Pengembangan "Desa Mandiri Energi" (DME) di Desa Sumber Bendo, Saradan Kabupaten Madiun. Jurnal Keteknikan Permintan service dan Biosistem (Volumr 4 no2), p 236 sd 125.

Taufiq, Ahmad dan Purwoko. 2013. Identifikasi Desa Mandiri Energi. Jurnal Ilmu Sosial. , vol. 12, no. 1, pp. 1-15, $\quad$ Feb. 2016. https://doi.org/10.14710/iis.12.1.2 013.1-15.

Wahyudi, Jatmiko, Tb. Benito Achmad Kurnani, dan Joy Clancy. 2015. Biogas Production in Dairy Farming in Indonesia: A Challenge for Sustainability. International Journal of Renewable Energy Development, vol. 4, no. 3, pp. 219-226, Oct. 2015

Widodo, Joko. 2009. Analisis Kebijakan Publik (Konsep dan Apikasi Analisis Proses Kebijakan Publik). Bayumedia:Malang.

Widyaninsih Wiwien. 2014. Partisipasi Masyarakat Melalui Desa Mandiri
Energi Berbasis Biogas Limbah Ternak Sapi Di Haurngombong Kecamatan Pamulihan Kabupaten Sumedang. Jurnal Ilmu Administrasi Volume XI Nomor 1: 28-51.

Wijayanti, Okta Evi. 2017. Analisis Kinerja Program: Dampak Pelaksanaan Program Desa Mandiri Energi (DME) Berbaisis Biogas dalam Peningkatan Keberdayaan Masyarakat Pengguna Biogas di Desa Purworejo Kecamatan Sanankulon, Kabupaten Blitar. Jurnal Kebijakan dan Manajemen Publik, 5(1), 1-7.

Wiyono, Gandjar.2014. Pelaksanaan Program Desa Mandiri Energi Berbasis Biogas dalam Rangka Pemberdayaan Masyarakat di Desa Sidomulyo, Kecamatan Pagerwojo, Kabupaten Tulungagung. Jurnal Administrasi Publik, 2 (5). Retrieved from

http://administrasipublik.studentjourn al.ub.ac.id/index.php/iap/article/view/ $\underline{465}$ 